\title{
EL HUMO DE VELA COMO ALTERNATIVA EN LAS ARTES VISUALES
}

\author{
SMOKE FROM CANDLES AS AN ALTERNATIVE TO VISUALARTS
}

Arturo Toledo Gonza ${ }^{t}$

\section{RESUMEN}

La presente investigación estudia la técnica del humo de vela como una alternativa en las artes visuales, en el que se utilizan elementos que no tienen un uso común o son residuales en las artes plástica. Este trabajo como forma de acercamiento del arte hacia la experimentación y observación tiene como convicción clara hacer de los materiales alternativos y utilizables como el uso del humo de vela, en elementos importantes que integren la obra de arte y que produzca sensaciones diferentes en el público, al observar un material cotidiano inusual(hollin) convertido en una expresión artística. La misión es resaltar la importancia de la técnica del humo de vela, de tal manera que se pueda unir ideas, pensamientos y sentimientos para la contribución al arte.

Palabras clave: Arte, experimental, vela, humo, hollin.

\section{ABSTRACT}

This research studied the technique of smoke from candles as an alternative in the visual arts, in which elements that have a common use or are residual in plastic arts are used. This work as an approach to art experimentation and observation has as clear conviction make of alternative and used materials, as the use of smoke from candles, important elements that integrate the artwork and produce different sensations in the public when they observe unusual everyday material (soot) become into an artistic expression. The mission is to highlight the importance of the technique of smoke from candles, so people can connect ideas, thoughts and feelings for the contribution to art.

Keywords: Art, experimental, candle, smoke, soot.

\section{INTRODUCCIÓN}

Se dice que el artista es el más cercano a nuestro Creador y continuador de su plan de creación. Es necesario además revestir las creaciones estéticas con una cultura artística que la civilización está hecha de continua evolución. Evolución quiere decir añadir nuevos descubrimientos a lo que los demás han hecho antes que nosotros, de la cual somos continuadores.

Con estas afirmaciones se inició con los primeros trazos de tizne en esta excéntrica aventura de hacer expresiones artísticas con el humo de vela (hollín), utilizado como pigmento. Desde tiempo atrás se pasó por varios experimentos y a medida que se ensayaba con diversos materiales alternativos, luego de muchos intentos y fracasos, por crear esta técnica, se incendió muchos formatos de papel y lienzo, en el dominio de la combustión del fuego y las manchas del hollín.

Al principio solo era una loca representación de la imagen al utilizar el humo de vela como pincel de cera, con cerdas de fuego, diría que fue fortuita, casual o acaso providencial. Aquel bendito día fueron redescubiertas las primeras manchas grisallas en la habitación llena de atmósfera espacial, donde vacilaban las aparentes formas que luego abandonarían su huella, como señal de existencia para la posteridad, desvelando las imágenes del interior del tizne y del espíritu del artista.

Francis Bacón decía en 1909, "el arte es la intensa persecución de la expresión del sentimiento interno por los medios plásticos una persecución intensa de ir llenando las formas insignificantes hay un impulso, una necesidad de expresarse en todo artista", citado por Sánchez (2006:4).

Otros artistas han trabajado con elementos descartables y materiales alternos, antes de los años 60, lo importante era trabajar con objetos de uso común o materiales inusuales, buscando armar con sus "escorias" y "acumulaciones" y protestar frente a la

\footnotetext{
'Licenciado en Arte. Facultad de Ingeniería Civil, Arquitecturay Geotecnia. Universidad Nacional Jorge Basadre Grohmann.

Correoelectrónico:azul.mipensamiento@hotmail.com
} 


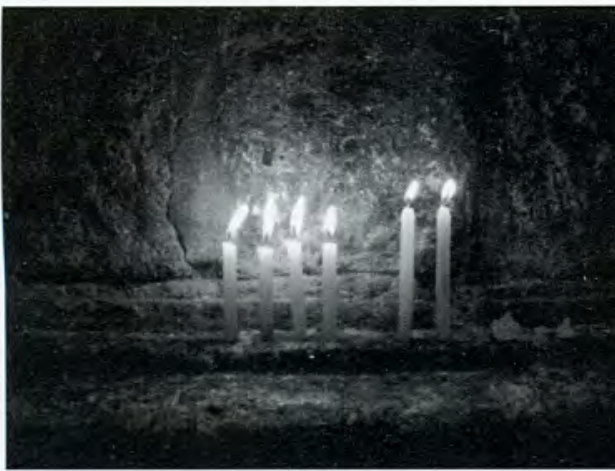

(a)

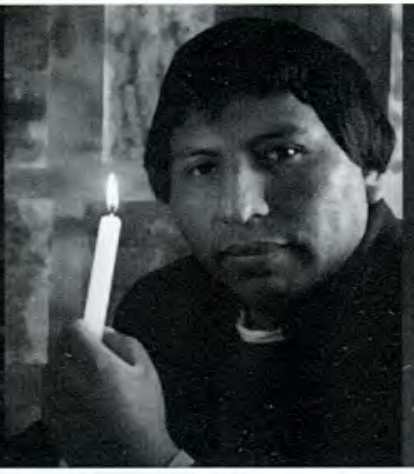

(b)

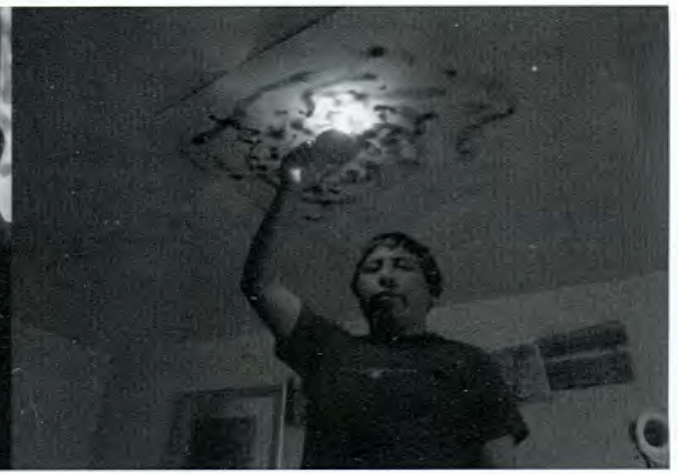

(c)

Figura $N^{\circ} 01$. Fotografías de desarrollo de la técnica

sociedad consumista, mediante sus "creaciones extrañas", hasta alcanzar la libertad que partiera de uno mismo y se expandiera por el mundo.

"El collage al fuego inventado por el artista Wolfgang Paalen en 1937 como técnica de escritura automática (surrealismo). Paalen marcaba con la llama de una vela trazos de tizne sobre un papel previamente coloreado, estos trazos eran resaltados más tarde en un proceso pictórico" (Thomas Karin, Diccionario del Arte Actual: 106).

\section{LA COMPOSICIÓN ARTÍSTICA ACTUAL}

Hoy es conocido por todos que el arte ha alcanzado un alto grado de independencia con respecto a las instituciones y poderes sociales. Ni las academias, ni la iglesia, ni cl Estado, ni cl público dictan ningún critcrio; cl artista goza de absoluta libertad creativa. Se vive una permanente experimentación y es bueno que se intcrrelacionen la ciencia, la técnica, cl arte, la música, la poesía, etc. Porque todo ello es expresión de vitalidad. Lo que preocuparía es que el público se quedara rezagado y se aferrará a un pasado irrecuperable.

El público asume la pintura como una expresión individual de su autor que no tiene por qué halagar el gusto de quien la contempla. El artista de hoy vive un estado de alerta permanente, cambia de asuntos, de técnicas, de métodos y no se estanca en una fase pasiva y vacía por considerar que ya tiene "su estilo" y asegurada su firma. La real función del artista creador es realizar algo que sea propio, que destaque y amplíc las fronteras del arte; algo que comparado con su producción anterior marque un avance.

Un pintor que no se muestre contento de su obra y reclame de sí mismo más y más scrá un auténtico artista creador, pero aquél otro que dice haber alcanzado ya su meta y que enseña sus cuadros a los demás con aire de genio insuperable no es otra cosa que un simple repetidor, el arte es inquietud, progreso y ansias de exploración. Hoy no existen objetivos comunes entre los artistas, no hay un estilo pre- dominante y es difícil encontrar criterios sólidos. Cada artista debe inventar sus principios y buscar sus particulares soluciones, sin saber si su actitud será entendida correctamente.

Este es el gran desafío del arte de hoy, inventar nuevos principios compositivos, rechazando todo lo anterior o también adoptar formas tradicionales y revitalizarlas haciéndolas vigentes e interesantes para el arte actual. En este sentido, la composición artística, es una aventura más incierta de lo que solía ser y el pintor debe saber que el tipo de composición que elija al realizar una obra de arte es sólo una posibilidad entre mil opciones distintas e igualmente válidas, opciones que van desde el realismo más estricto a la abstracción, desde el cultivo de las temáticas tradicionales, hasta la representación de escenas contemporáneas, recurriendo a cualquicr tipo de soporte o materiales y cualquier tipo de técnica como el collage, video-arte, arte póvera, etc.

Y del mismo modo el artista puede valerse de su intuición, su angustia, de su inconsciente, de la razón, de lo absurdo y de su existencia misma. Siempre será preciso superar obstáculos, movilizar la imaginación y mantener la mente en constante actividad para explorar y descubrir.

Según el gran artista chino del siglo X Chin Hao dijo: "Cuando la actuación del espíritu es débil, todas las formas serán defectuosas y aunque el pincel se mantenga activo lo que este produzca será cosa mucrta", refirićndose a sentir y expresar. (Nueva Biblioteca Filosófica.1978:160).

El fundamento esencial de la composición artística, como de todo lo que realmente importa en cl arte, está en la intuición del autor, en su conocimiento y en su experiencia de haber conocido los principios de cquilibrio, tensión, contraste y unidad variedad.

\section{LA TÉCNICA DEL HUMO DE VELA}

Con la técnica del Humo de Vela como alternativa en las artes visuales propongo e impulso al reciclaje y a la experimentación con materiales 


\section{La Vida y la Historia}

Toledo, A. El Humo de Vela como Alternativa en las Artes Visuales

alternativos en el arte. Si bien la labor del artista es expresar, también es difundir sus pensamientos de modo que se conviertan en una cadena social, como una forma más de concientización con el único fin de motivar e innovar las ideas y la creatividad en las arte.

La técnica del humo de vela es una alternativa de expresión de uso no común en el trabajo artístico, en donde se utiliza como pigmento el "hollín" que emana de la vela encendida. Afirmo que la riqueza del hollín es un elemento maleable fácil de manejar que se adapta a diferentes soportes en especial en el formato blanco, también permite fabricar formas variadas, crear texturas visuales, belleza monocroma, volúmenes, tonalidades de claro oscuro y sensaciones de espacios atmosféricos con nitidez. A su vez la obra causa diferentes emociones y sentimientos en la cual se convierte en el agente responsable de la sensibilización al público.

La obra hecha con el pigmento del hollín es beneficioso por sus bajos costos de los materiales a comparación de los materiales convencionales como la pintura al óleo, acrílico, acuarela, etc.

En la actualidad no existe una investigación formal sobre la técnica del humo de vela en donde resalte su importancia y la originalidad. Por la cual escribí el texto denominado "El Arte del Humo de Vela", patentando en INDECOPI siendo inédita.

\subsection{La Construcción del Arte con el Humo de Vela}

\section{Aclaración del Pensamiento}

- Hume-Arte: Es el acercamiento al espiritualismo de la luz interior a la imagen de la palabra, la relación que co-existe en el uso del humo de vela como un vehículo de comunicación de mensajes y símbolo de esperanza, esto justificaría nuestro gran proyecto de existencia.

- Arte: Es continuar con la creación del aliento de vida del espíritu.

- Humear: Es una alternativa como pigmento, acción de trance en regocijo de dejar marcas de huellas de tiznes, en un espacio requerido, formas de creación fortuita del sub-consciente espiritual.

- Des-velar: Técnica de descubrir las imágenes del interior del tizne a través del humo de vela con una barra de goma, es flexible y se adopta a las formas sugeridas por el artista.

\subsection{El Proceso de la Magia del Humo de Vela}

\section{"Reflejo de la luz y las creaciones del tizne" \\ En primer lugar, empezaremos a tiznar y los dejaremos actuar sobre la base del formato blanco del papel, utilizando un esquema muy simple y planteando de la forma más sencilla posible.}

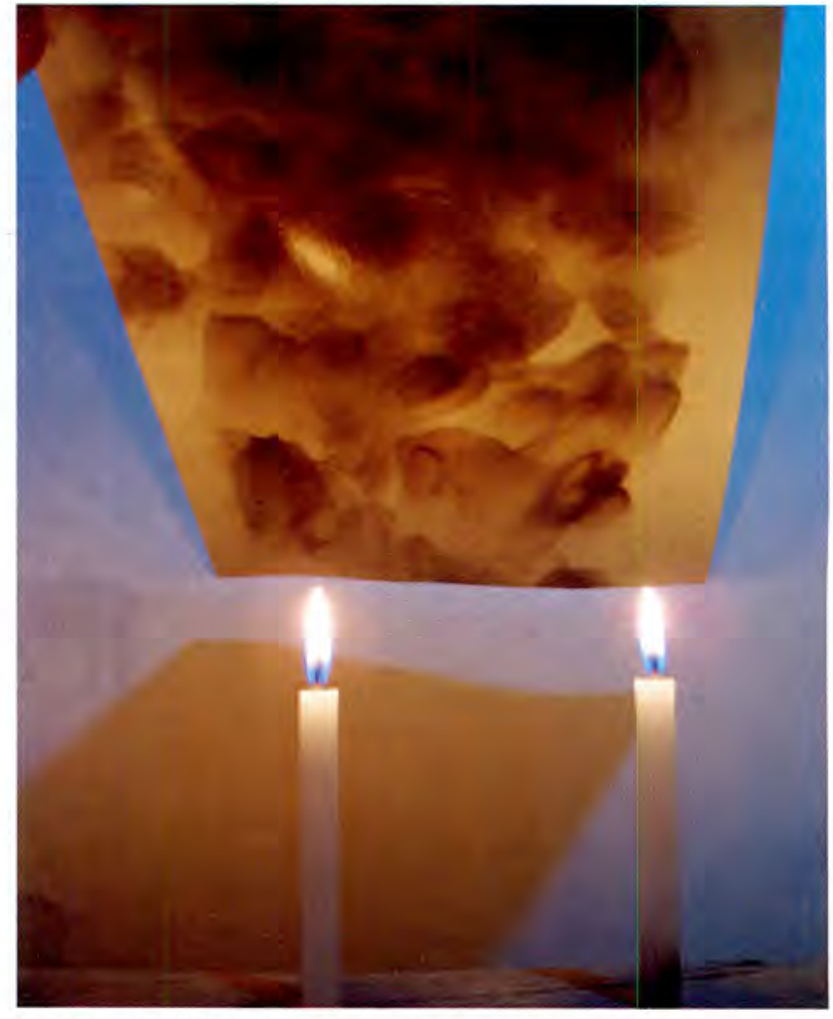

Figura $\mathrm{N}^{\circ} 02$. La técnica de humear

De este modo, cada componente del efecto del humo de vela posee cuatro umbrales principales para armar una obra de arte.

- Suavidad y aspereza del pigmento.

- Claridad y oscuridad del valor tonal.

Después de haber tiznado la base del formato, seremos los buscadores del interior en lo exterior, crearemos impresiones espirituales y concebiremos la forma que se esconden en el espacio de las sombras del hollín, de las cuales serán reveladas las imágenes a través de la percepción.

\section{Fabricación de la forma}

Empezaremos por observar las huellas del tizne originadas por la combustión de la vela en considerable detenimiento, este paso es lo más importante de este proceso, se localizarán las formas que nos "anuncian" su luminosidad tonal del humo, una vez descubiertas comenzaremos a la construcción de identificar y esbozar las imágenes, para luego emborronar (técnica décollage) las texturas imprecisas o partes de la figura deseada, buscando contrastes de volúmenes entre el fondo y la figura de la obra, luego se procederá para su acabado final: El de proteger y fijar con una laca de barniz para la posterioridad.

\section{La técnica y el espacio de gestación}

Se puede aplicar de acuerdo a su esencia de origen que consiste en utilizar la emanación del fuego 
como pincel, los soportes deberán ser establecidos en el techo de la habitación del atelier, seguidamente se iniciará a dibujar con los trazos de tiznes que despegan de las velas en los espacios requeridos, de acuerdo a la intensidad tonal del claro oscuro, se graduará con la aproximación y el alejamiento de la vela de abajo hacia arriba.

\section{Los soportes}

Todos los soportes son válidos, pueden ser de diferentes variedades, desde los más sólidos hasta los más dóciles, como papel, plástico, lienzo, arcilla, metal, telilla, madera, pared entre otros. El humo de la vela se adhiere en cualquier espacio por su flexibilidad, pero los más apropiados son los diferentes papeles de cierto grosor y bastante lisos donde se impregnan exitosamente sin ningún problema.

\section{ANÁLISIS Y DESCRIPCIÓN DE LAS OBRAS}

\subsection{Apariencias de Identidad}

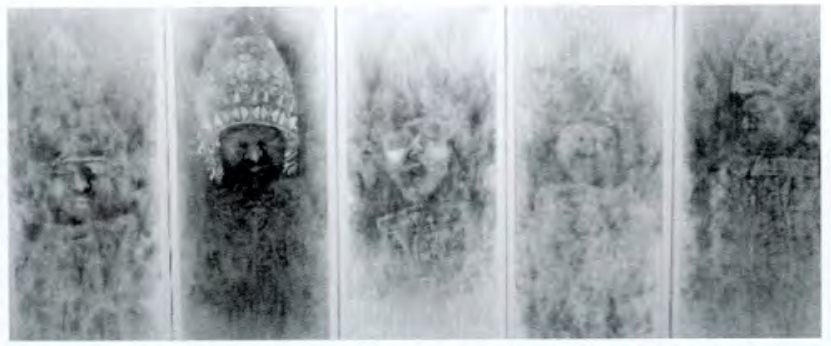

Figura $\mathrm{N}^{\circ} 03$. Obra Apariencias de Identidad

\section{Fichaje de la Obra \\ Soporte : Lienzo \\ Formato : Políptico $85 \mathrm{~cm} \times 170 \mathrm{~cm}$ \\ Fecha de ejecución : : 15 mayo 2008}

\section{Análisis semántico personal:}

En esta obra se configura como punto principal las expresiones gestuales de los rostros de facciones indígenas en trance de dolor, que sumergen de las humareadas que emanan del aliento de las velas. Se puede apreciar los detalles quemados por la llama de un fósforo dejando una tonalidad de claro oscuro en las formas. La posición del formato en dirección ascendente contribuye a la composición de la obra.

\subsection{Rompecabezas}

\section{Fichaje de la Obra}

Soporte

: Papel

Formato

: $60 \mathrm{~cm} \times 89 \mathrm{~cm}$

Fecha de ejecución

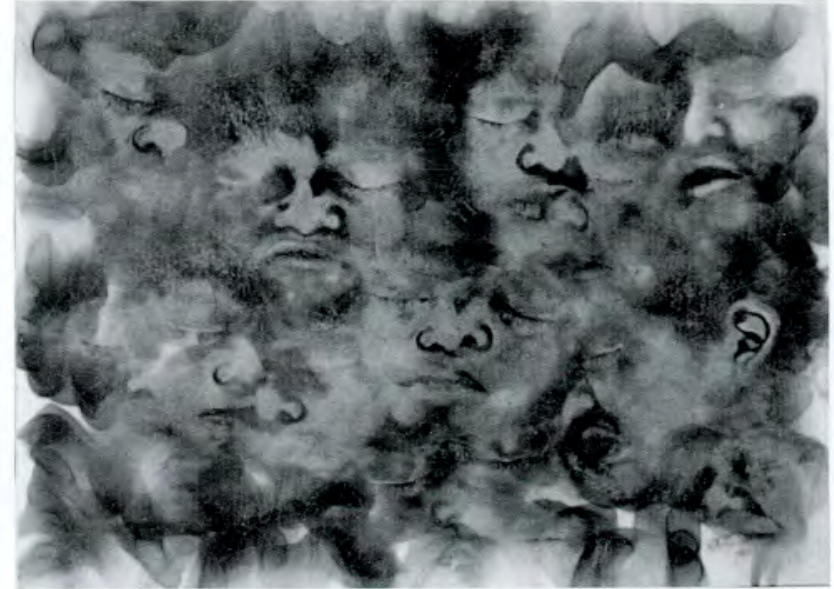

Figura $\mathrm{N}^{\circ} 04$. Obra Rompecabezas

\section{Análisis semántico personal:}

La fusión de las imágenes en el formato visibiliza la asociación de sonidos tonales en los espacios determinados, los sentimientos que transmiten sublimidad; se puede observar claramente la expresión de las formas y la fuerza del valor que afrontan por sobrevivir cuando el humo se adhiere en la tela en señal de despertar.

\subsection{Suavización Celestial}

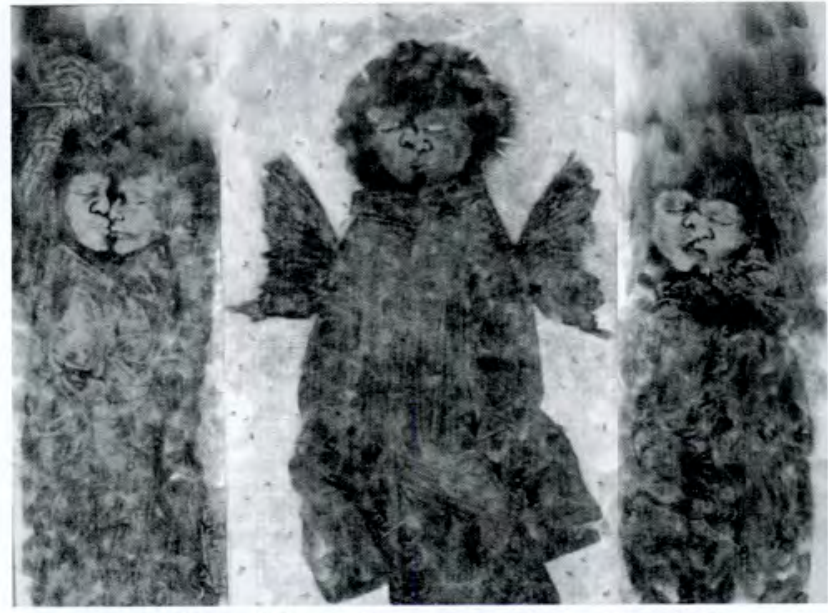

Figura $\mathrm{N}^{\circ} 05$. Obra Suavización celestial

\section{Fichaje de la Obra \\ Soporte : Lienzo sobre bastidor \\ Formato : Tríptico $100 \mathrm{~cm}$ x $160 \mathrm{~cm}$ \\ Fecha de ejecución : : 21 enero 2009}

\section{Análisis semántico personal:}

Suavización simboliza la metáfora visual de niños suspendidos en un sueño. Al unir las imágenes podemos sentir la exaltación de las formas como punto concéntrico, la representación de seres alados construidas en la dualidad de materia y espíritu, también se pueden considerar la expresión de las 


\section{La Vida y la Historia}

Toledo, A. El Humo de Vela como Alternativa en las Artes Visuales

imágenes y la fuerza que transmite el contenido visual. Al hablar de celestial también citamos a lo divino.

\subsection{Expo-lítico}

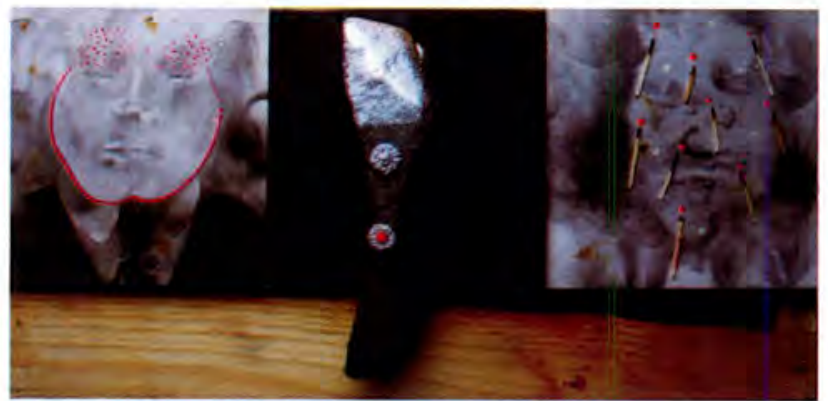

Figura $\mathrm{N}^{\circ} 06$. Obra Expo-lítico

\section{Fichaje de la Obra}

Soporte : Lienzo sobre bastidor

Formato : Ensamblaje $20 \mathrm{~cm} \times 20 \mathrm{~cm}$ detalle.

Fecha de ejecución : :03 agosto 2013

\section{Análisis semántico personal:}

El ensamblaje de los elementos reciclados impulsa a la obra a ser dinámico en la expresión compositiva; la piedra posee vida, como punto principal insinúa el diálogo de los semblantes y los puntos de color rojo genera vibración en la obra, también se puede apreciar las texturas visuales producidas por la combustión del humo de vela y las texturas palpables conformada por los elementos orgánicos.

\subsection{Alumbramiento de $\mathrm{Fe}$}

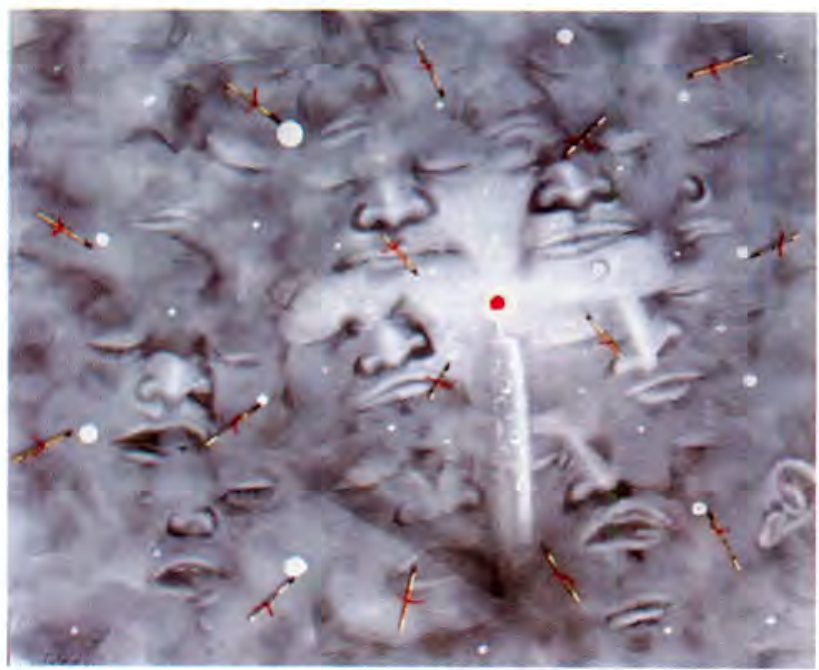

Figura $\mathrm{N}^{\circ} 06$. Obra Alumbramiento de $\mathrm{Fe}$

\section{Fichaje de la Obra}

$\begin{array}{ll}\text { Soporte } & : \text { Lienzo } \\ \text { Formato } & : 45 \mathrm{~cm} \times 60 \mathrm{~cm}\end{array}$

Fecha de ejecución : :06 junio 2010

\section{Análisis semántico personal:}

El proceso de construcción de esta obra es muy significativa por la buena voluntad de participación de personas con creencias en su fe, escribiendo imágenes textuales en cada palito de fósforo, mensajes direccionados hacia un punto luminoso que es representado por colores de reclamo, en busca de la luz de luz que es Jesús.

\section{APRECIACIÓN ESTÉTICA}

Cesar Cornejo, Doctor en Artes de University South of Florida, da una apreciación sobre la técnica del humo de vela del autor:

"Arturo Toledo Gonza trabaja con humo, un material no utilizado por ningún pintor en el Perú o el extranjero. Él nos presenta un camino a un mundo caracterizado por el ritual que realiza para producir cada una de sus pinturas. Toledo Gonza, es dueño de una creación única que tiene elementos rituales que se remontan a prácticas religiosas y ancestrales. Es inevitable pensar en el artista confrontado con el lienzo o papel, en un espacio íntimo de connotación mística, en el que el tiempo y el movimiento efectuados son también parte del trabajo. Toledo Gonza, posee las llaves de este mundo personal en el que él es el maestro máximo. Esta revelación nos llega en un momento inimaginable el arte atraviesa una etapa en la que la velocidad vertiginosa es simultánea, la información es procesada día tras día, que nos impide detenernos a mirar con calma, y se necesita más que la inmediatez de la imagen para poder explorar el ritual detrás de una obra como la que produce Toledo Gonza. Sin embargo, es $\tan$ fuerte y $\tan$ rica su propuesta que el tiempo se detiene al observarla, y empezamos a investigar en la profundidad de las imágenes y vemos al artista que se oculta detrás de la superficie de formas sutiles que él nos presenta en cada uno de sus trabajos pictóricos.

Esa experiencia de penetrar con la mirada los diferentes planos de los que sus obras están constituidas es un viaje personal e íntimo cuyo destino es la revelación que Toledo Gonza nos presenta. La obra es al final la única evidencia de un acto que al igual que quien deja marcas en el agua por pocos segundos hasta que luego se desvanecen, él realiza con gran maestría en el soporte con humo que luego también desaparece, pero dejando atrás la evidencia sobre el soporte del papel o lienzo de los movimientos de aproximación y alejamiento de la superficie que 


\section{La Vida y la Histaria}

\section{Toledo, A. El Humo de Vela como Alternativa en las Artes Visuales}

él ha realizado. Su proceso creativo, además, redefine la relación espacial entre el artista y el soporte al igual que en su tiempo lo hizo Jackson Pollock, pero a diferencia de él que lo hace sobre el piso sino fijada en altura, para permitirle trabajarla desde abajo. Esta manera única de redefinir la relación del artista y su soporte se refleja en la sutileza que poseen las formas que componen su trabajo. Su obra atrapa la tradición espiritual de siglos en un instante creativo y la macstría con que Toledo Gonza ejecuta sus trabajos, es el legado de esas generaciones lejanas que pacientemente presenciaron las formas que tomaban el humo en rituales religiosos que a diferencia de los sacerdotes y chamanes, él consigue perennizar en un medio para la posteridad y para nuestra admiración."

\section{REFERENCIAS BIBLIOGRÁFICAS}

Nueva Biblioteca Filosófica "La Voluntad de Creer" Printed in Argentina, Edición 1978

KANDINSKI Vasili. "De lo Espiritual en el Arte" Editorial Labor, S.A. Colombia. Tercera Edición 1992.

LEXUS. "Historia del Arte". Ediciones Nauta C. S. A. España. Edición 2001.

LLOBERA, José. "Dibuja, pinta y modela" Editorial AFIIA. Internacional, S.A. Barcclona. Edición diciembre 1975.

SANCHEZ Q. José, "Ecce Homo Transeúnte". Sin editorial, cusco Perú 2006

THOMAS, Karin. "Diccionario del Arte Actual". Editorial Labor, S.A.

THOMAS, Karin. "Hasta Hoy" Estilos de las Artes Plásticas en cl siglo XX. Ediciones del Serval - España. Primera Edición: abril de 1988 . 